\title{
Choose Your Adventure: A Library Reorganization Case Study
}

\author{
C. Heather Scalf \\ University of Texas Arlington, USA
}

\begin{abstract}
In 2013, after extensive learning, scanning, and planning, and armed with a new vision, the UT Arlington Libraries underwent a comprehensive reorganization. In order to facilitate this, the leadership team had to determine what kind of roles would be required to achieve the new vision and accomplish the new objectives, and what skills and characteristics would be necessary in those roles. The entire staff was then asked to engage with the reorganization process by participating in two surveys that would allow them to self-evaluate and reflect on their skills and desired roles. All positions were structurally agnostic and nearly every position was on the table.
\end{abstract}

After individual interviews with the dean of libraries, staff at all levels were notified of their new roles. Although a great deal of communication and preparation had gone into the work beforehand, the transition itself was not without difficulty. This paper will discuss the process that was used and some of the resulting lessons learned.

\section{Introduction}

In 2012, a new dean of libraries was hired at UT Arlington, with innovation and change being her watchwords. The search committee, which included five library staff, sought out candidates who had a perspective on user needs, both current and future, and who were committed to doing the work to make the libraries more relevant to our community. The new dean brought a strong user focus as well as a futureoriented perspective. The 2012 Association of College and Research Libraries (ACRL) Research Planning and Review Committee report, required reading for the leadership team after the dean's arrival, revealed the top 10 trends common to academic libraries, based upon the current literature. While all of them struck a chord, the three most immediately relevant were communicating value, prioritizing user behaviors and expectations, and patron-driven acquisition. Our need to communicate value was clear, as the libraries were experiencing some ill effects to changes made by the university that were made without our input (e.g., the dramatic increase in student enrollment in an exclusively online evidence-based RN to BSN degree program). When designing the fee structure for the program, no library fees were included, so enrollmentbased database subscription prices increased with no additional income to the libraries. A comprehensive evaluation of print collection use for purchases made in the previous 10 years, combined with rising inflation in e-resource subscription costs that had been affecting academic libraries across the country, necessitated a change in our monographic acquisition policy from "just in case" to "just in time," driving us to adopt a completely patron-driven monographic acquisition model. The changing priorities and unspoken needs of our users drove extensive exploration and reprioritization of library assets. Soon after her arrival, the dean created charges for nine task forces, which more than $80 \%$ of the library staff volunteered for, to accomplish activities that ranged from environmental scans for best practices in academic libraries to extensive ethnographic studies to learn more about student research needs. Not only would this information provide context and a framework for the changes to come, it also helped staff to develop a broad understanding of the needs of our community and the importance of pursuing a new direction. Using all of the information gathered from the task force work, a list was developed that was locally titled, "What we know, and what we think." This list identified some broad themes about user needs and expectations, allowing us to think differently about our services. Combined with data provided from external sources such as the National Survey of Student Engagement and the annual Student Experience Survey administered by the university's institutional planning office, a new vision was defined for the libraries: Creation, Collaboration, Exploration and Innovation (C2XI). The initial plan was to complete the process of reorganization in three months and allow for staff transition during the summer semester, in order to minimize impact on our users. 


\section{Planning}

After identification of the vision, the leadership team developed a list of the kinds of knowledge and skills that staff would need in order to accomplish the goals of the new vision. Guiding questions were, "If we want to accomplish X, what are the components of that activity? What do staff need to know how to do?" We also asked, "What kind of preferences might a person have who might be good at a particular task or role, even if they don't currently have the skill?" This was not an inventory of skills held by current staff, but rather a brainstormed list of what would be required in order to complete potential actions and activities as part of the new vision. For example, proficiency with Geospatial Information Systems and open source programming were listed, as well as web design skills and use of analytic tools. Along with proficiencies, a list of preferences was also developed. Examples of this include working with certain types of constituents and communication preferences. Would the staff member say that they preferred or avoided working with undergraduate students, or that they loved doing number crunching or creating marketing materials? After a day of brainstorming skills and preferences, the team began to combine these skills into groups that would be critical in the performance of certain functions, and then group the functions into roles. Along with the role, workloads were described and defined based upon immediate priorities and, in some cases, the need for multiple staff in certain roles was clarified. The resulting list of $283 \mathrm{KSAPs}-$ knowledge, skills, abilities and preferences-was combined into a total of 63 specific roles, which all staff would have an opportunity to engage with in the days to come.

Once the vision had been identified and the KSAP process defined within the leadership group, department coordinators (heads) began to have meetings with their staff to discuss the planning process and next step for the organization. While it had been generally understood by the staff that a reorganization was the most likely result of the work of the previous year, there was still a great deal of trepidation about how that would take place. A decade prior, a reorganization that had very little transparency had had long lasting negative effects on the culture of the libraries. Because of this, there were still lingering fears on the part of staff who remained at the current time, so communication was paramount to the success of the process. Throughout the previous year, the dean had been sharing weekly email updates about what was happening with the various task forces and what was being learned, as well as providing resources for staff to engage with to help them see the bigger picture and have more clarity about the general direction that the libraries would be taking. All library staff were encouraged to read Jim Collins' book Good to Great to understand the approach that we were taking, along with Brian Mathews' white paper "Think Like a Startup." During the planning retreat, the dean sent daily emails documenting the progress and explaining and celebrating the new vision of C2XI. Once the roles and the process were defined, it was the job of department heads to answer questions and provide support during the time leading up to and through the transition.

Once the KSAP was completed and the roles defined, surveys were created and then sent to all staff in order to give them a chance to indicate their skills and preferences, as well as to choose desired roles. Figures 1 and 2 provide samples of the survey questions that staff responded to. 
Figure 1. KSAP Preferences

KSAP Skills and Workstyles Preferences Self-Assessment

Workstyles Preferences Self-Assessment

This is a section where you say what your preferences are for a wide variety of situations and aspects of work here in the library. It focuses on what you enjoy rather than what you know.

REMEMBER: there are NO RIGHT OR WRONG ANSWERS. Please be honest! Nobody enjoys everything, and that's ok!

* PR1 Communicating via email

1 Dislike 2 Enjoy a little 3 Enjoy a lot 4 Love this! 0 Not Sure

* PR2 Communicating via IM/txt

1 Dislike 2 Enjoy a little $\quad 3$ Enjoy a lot 4 Love this! $\quad 30$ Not Sure

* PR3 Communicating by phone

1 Dislike $\because 2$ Enjoy a little $\quad 3$ Enjoy a lot 4 Love this! 0 Not Sure

Figure 2. KSAP Preferences

\begin{tabular}{|c|c|c|c|c|c|}
\hline \multicolumn{6}{|c|}{ * PR107 Analyzing large amounts of data } \\
\hline 1 Dislike & 2 Enjoy a little & 3 Enjoy a lot & $\varnothing$ & 4 Love this! & 0 Not Sure \\
\hline \multicolumn{6}{|c|}{ *PR108 Teaching information literacy skills } \\
\hline 1. Dislike & r. 2 Enjoy a little & 3 Enjoy a lot & फ & 4 Love this! & 0 Not Sure \\
\hline \multicolumn{6}{|c|}{ *PR109 In-depth faculty and PhD student research } \\
\hline C 1 Dislike & (2) 2 Enjoy a little & 3 Enjoy a lot & $\theta$ & 4 Love this! & 0 Not Sure \\
\hline \multicolumn{6}{|c|}{ * PR110 Answering statistics, data, or GIS questions } \\
\hline 1 Dislike & 2 Enjoy a little & . 3 Enjoy a lot & 6 & 4 Love this! & 1. 0 Not Sure \\
\hline
\end{tabular}

After completing the KSAP survey, staff were provided a list of all 63 roles available, along with a description of each role, and asked to list their top 7 choices and their bottom 5 choices. The dean had committed to all staff that they would not be given a role in their bottom 5 , so this was an opportunity for all to indicate roles that they felt were not a fit for their skills and preferences. Staff completed the surveys over a two-week period, and once they were all submitted, the dean began meeting with each staff member individually. This individual discussion of their preferences and role choices allowed each person to have an opportunity to articulate their ideas about why they selected or did not select a particular role and to give them an opportunity to reprioritize the order of choices, if they so desired. In some cases, there was additional discussion about the specifics of a role that provided additional context to the staff member, which resulted in a change in their choices. These meetings took a total of four weeks to complete. After the interview process, the dean assigned staff to the newly created, or revised, roles. Figures 3 and 4 show examples of the results of the role selection survey. 
Figure 3. Top 7 job choices sample.

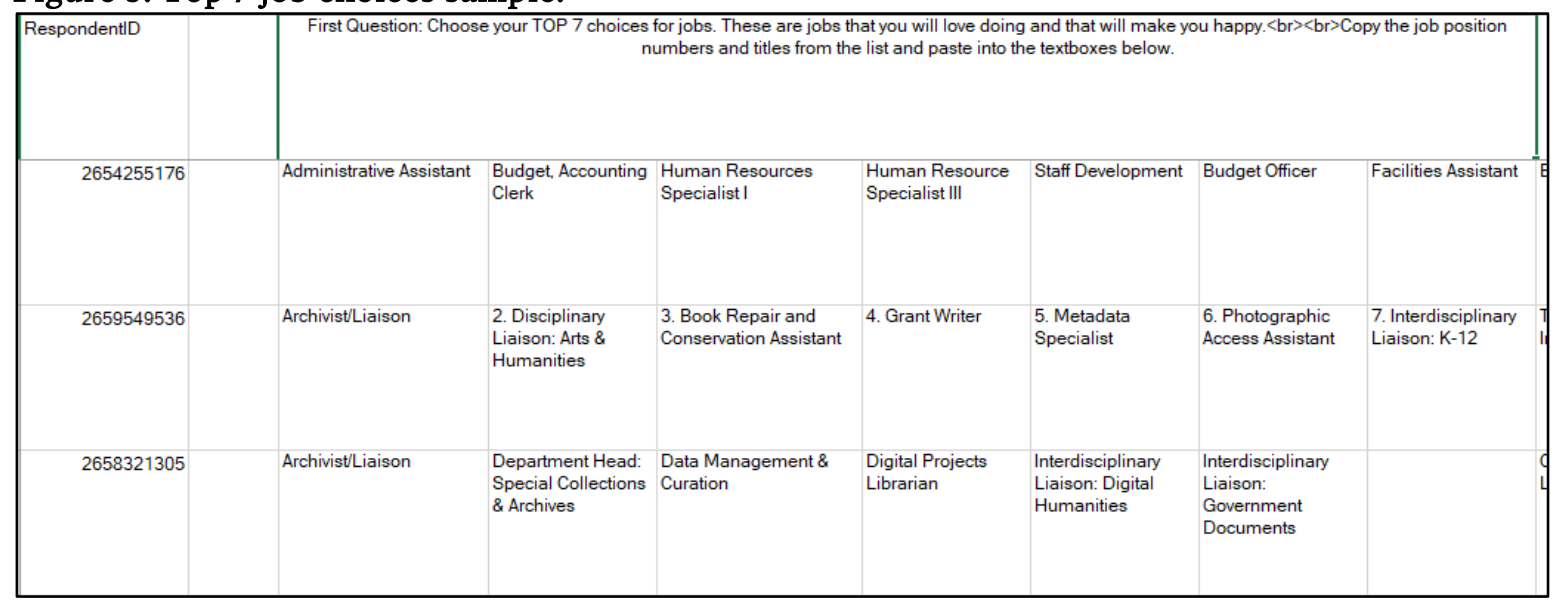

Figure 4. Bottom 5 job choices sample.

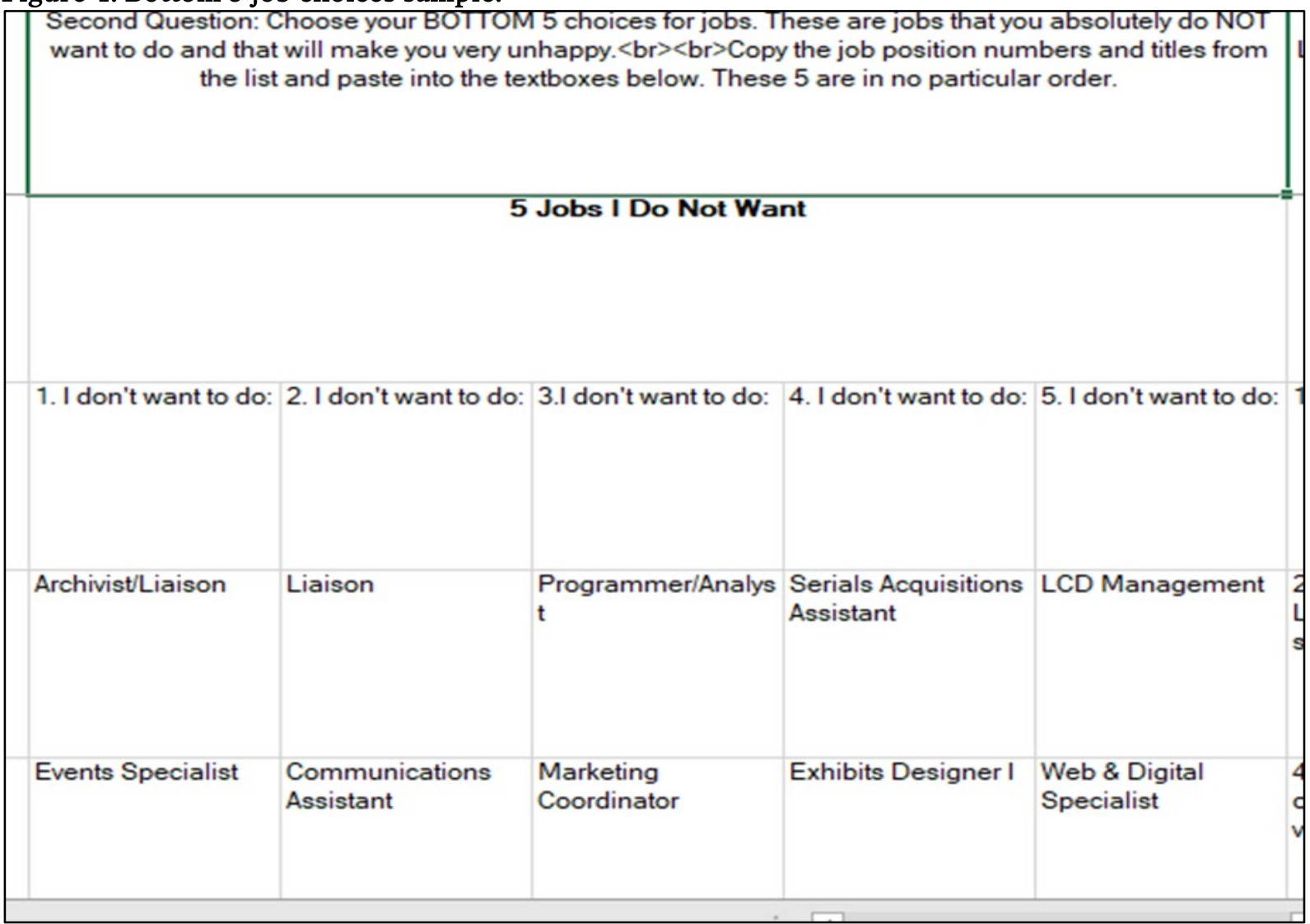

\section{The Result}

Two months later, all staff were notified about their future roles via email, with the leadership team being notified on Friday and the remainder of the staff notified the following Monday. In the end, 87 percent of staff got a role that was in their top three, with 63 percent getting their top choice, and no one was permanently assigned to a role that was in their bottom five. Because the timeline had been delayed a bit, transitions for staff into new departments would have to take place in the few weeks prior to the beginning of the new semester. There were many staff who underwent significant change, moving from library assistant positions to librarian or archivist roles, or from one functional area to a completely different one 
during the reorganization. Additionally, a number of staff chose and were placed into roles that did not previously exist in the organization, such as marketing and graphic design.

The new leadership team created by the reorganization had its first meeting the day after all staff received their notifications, in the form of a two-day leadership development retreat. The overall organizational structure was revealed to the leadership team at the retreat. After clarification and discussion about how the structure would support the achievement of C2XI, the structure was released to all staff at the end of that week. After the two-day training, previous department coordinators then met with the staff in their old departments individually to facilitate the transition by explaining roles and answering transition-related questions. One of the key elements that the dean wanted the leadership team to convey to staff was that the change was not an indictment of the past, but a need to focus on the future.

Over the course of the next month, staff began transitioning to new departments as spaces were redefined and supervisory relationships were clarified. While it would seem that there would be plenty of time for organizational transitions, several issues arose that complicated the process for both staff and library users.

\section{Lessons Learned}

One lesson learned after the process was complete was that it is critically important to manage expectations in a time of transition. There were some service challenges inherent in such dramatic change that were exacerbated by the perception of some staff that the transition was as simple as stepping from one role into another, without consideration for the needs of library users. For example, there had previously been five open librarian positions prior to the reorganization. Likewise, there were 10 department coordinators. In the new organization, there were 15 directors or department heads, with many of the new leaders coming from the liaison ranks. The combination of these promotions with preexisting empty positions meant that there was a significant lack of librarians to act as department liaisons once the fall semester began. In an effort to ameliorate this, the dean temporarily assigned liaison duties to four librarians who had indicated that this role was in their bottom five choices. While this was only a temporary measure, the expectations of those four staff were significantly disappointed. Likewise, because of the way that public services were restructured (from four departments into one, with previous access services department functions such as ILL, stacks management, and reserves and resource delivery services being moved to a non-public services department, access and discovery), staff who had had a $20 \%$ assignment to a service desk no longer had that responsibility in their new role. Along with the combination of the four service points into three desks run by a single department, it was necessary for staff to continue to support public services in their new roles, in spite of their expectations and their new job descriptions. In addition to staffing needs, new assignments also meant that there was a significant amount of training required in order for staff to be proficient in their new roles. In some cases, staff have chosen to move or been moved involuntarily to different roles for a better fit, and departments have been created, shifted, or realigned to move strategic priorities forward. While every effort was made to honor a staff member's passions in the initial assignments, in some cases, the staff did not have, and could not learn, the necessary skills or abilities, requiring additional role changes and adding personal stress to staff who were struggling to adapt to the new priorities.

Additionally, while there was great attention paid to the need for communication in the planning process, once the organizational change actually happened, the libraries' $24 / 5$ operational needs took priority and progress in some areas stalled. In order to overcome many of the transitional issues in the short term, it was necessary to communicate more frequently. When that did not happen, organizational stress increased and productivity decreased.

\section{Conclusion}

One of the guiding principles for the libraries is "perpetual beta," and the organization itself has continued to change and develop as staff have since chosen different roles for a better fit in some cases, or as new departments have been formed to move strategic priorities forward. While the design and execution of the reorganization process was as transparent and inclusive as it could possibly be, with every attempt made to be data driven, the human element must not be forgotten in the execution of the plan. As the dean of libraries 
recently said in a staff meeting, "All of the data in the world doesn't make change easier." Even change that is welcomed and accepted is not without its challenges, and there continue to be difficulties in hiring and staff retention. The new organization is dramatically changed and its focus has changed to reflect new priorities. Rather than information literacy, the new priority is experiential learning and maker literacies. The monographic collection is built on demand, rather than speculatively, with a bias toward e-books. Team compositions changed, leadership changed, and $90 \%$ of the staff have roles that were not imagined in the prior organization. Most staff, including management, needed to develop new skills, and this caused a high level of uncertainty across the organization. With a focus on innovation and perpetual beta, expectations frequently shift, creating additional communications challenges. New programs and services have been developed and implemented and some increase in staff engagement and support is evident. The innovative approach to role design and staff participation was key to a strong beginning. Ongoing change management continues to be a work in progress.

-Copyright 2019 C. Heather Scalf 